\title{
Underground cabling and marking of power lines: conservation measures rapidly reduced mortality of West-Pannonian Great Bustards Otis tarda
}

\author{
RAINER RAAB, CLAUDIA SCHÜTZ, PÉTER SPAKOVSZKY, EIKE JULIUS \\ and CHRISTIAN H. SCHULZE
}

\begin{abstract}
Summary
Collisions with power lines represent an important mortality factor for Great Bustards Otis tarda throughout the distribution range of the species. This study evaluates the success of two conservation measures implemented in the West-Pannonian distribution range to reduce the number of power line collision casualties: (I) extensive underground cabling of $43.1 \mathrm{~km}$ power lines, and (2) marking of $89.7 \mathrm{~km}$ power lines starting in 2005 and 2006, respectively. The mortality rate of Great Bustards in our study area (covering $686.5 \mathrm{~km}^{2}$ ) decreased significantly between 2002 and 2011, predominantly caused by reduced mortality due to power line collisions. Univariate tests indicate that underground cabling and power line marking significantly decreased power line collision casualties. Generalised linear models (GLMs) highlighted the prominent effect of underground cabling. Our results indicate that five years after underground cabling and marking of power lines within core areas of the West-Pannonian distribution range of the Great Bustard, the population already benefited through a significantly decreased mortality rate. Both conservation measures most likely contributed strongly to the rapid recovery of the West-Pannonian Great Bustard population observed within the last decade.
\end{abstract}

\section{Introduction}

The Great Bustard Otis tarda is a globally threatened bird species classified as 'Vulnerable' by IUCN (2010). Its West-Pannonian population declined significantly during the second half of the last century but increased again from 130 birds in 1995 to 376 individuals in the winter 2008/ 2009 due to the implementation of various conservation measures (Raab et al. 2010). However, some remaining threats still cause substantial mortality of Great Bustards. Particularly, power line collisions occurred quite frequently during the last decade and were responsible for $41 \%$ of all West-Pannonian bustards found dead (Raab unpubl. data).

Man-made structures such as tall masts for television and mobile phone, wind turbines or power lines can cause harm to birds in many ways: habitat loss due to disturbance, disruption of local (or migratory) movements or - even more severe - injury and death through collisions (Ballasus and Sossinka 1996, Barrios and Rodríguez 2004, Bevanger and Brøseth 2004, Haas et al. 2006, Newton 2007, Drewitt and Langston 2008, Rollan et al. 2010). Mortality due to collisions with power lines involves a broad range of bird species (Janss 2000, Bevanger and Brøseth 2004, Frost 2008), but evidence exists that large species considered as "poor flyers" are particularly sensitive to collisions with man-made structures. Small and broad wings combined with high wing load prevent rapid and appropriate reactions to unexpected obstacles (Bevanger 1995, 1998, 
Janss 2000). Therefore bustards are among the commonly recorded victims of collisions (Janss 2000, Reiter 2000, Lane et al. 2001, Alonso et al. 2005, Martín et al. 2007).

To mitigate the high collision risk for these species, enhancing the contrast of wires against the background by using power line markers or avian flight diverters (Alonso et al. 1994, Brown and Drewien 1995, De La Zerda and Rosselli 2003, Frost 2008, Yee 2008) and underground cabling (Drewitt and Langston 2008) have been recommended as conservation measures.

Power line collisions represent a major mortality factor for Great Bustards Otis tarda, although they are able to adapt their flight behaviour (Raab et al. 2011). In the framework of the LIFE project LIFEo5 NAT/A/oooo77 for protecting the West-Pannonian population of the Great Bustard (www. grosstrappe.at) two conservation measures were implemented to decrease the risk of collision with power lines: (I) extensive underground cabling (starting in 2005) and (2) marking of power lines (starting in 2006). In this article, we present a comparative evaluation of both mitigating measures.

\section{Methods}

\section{Study area}

The study area of $686.5 \mathrm{~km}^{2}$ covered most of the current distribution area of the West-Pannonian Great Bustard population in Eastern Austria and Western Hungary (Fig. 1). A more detailed description of the area is provided in Raab et al. (2010, 2011).

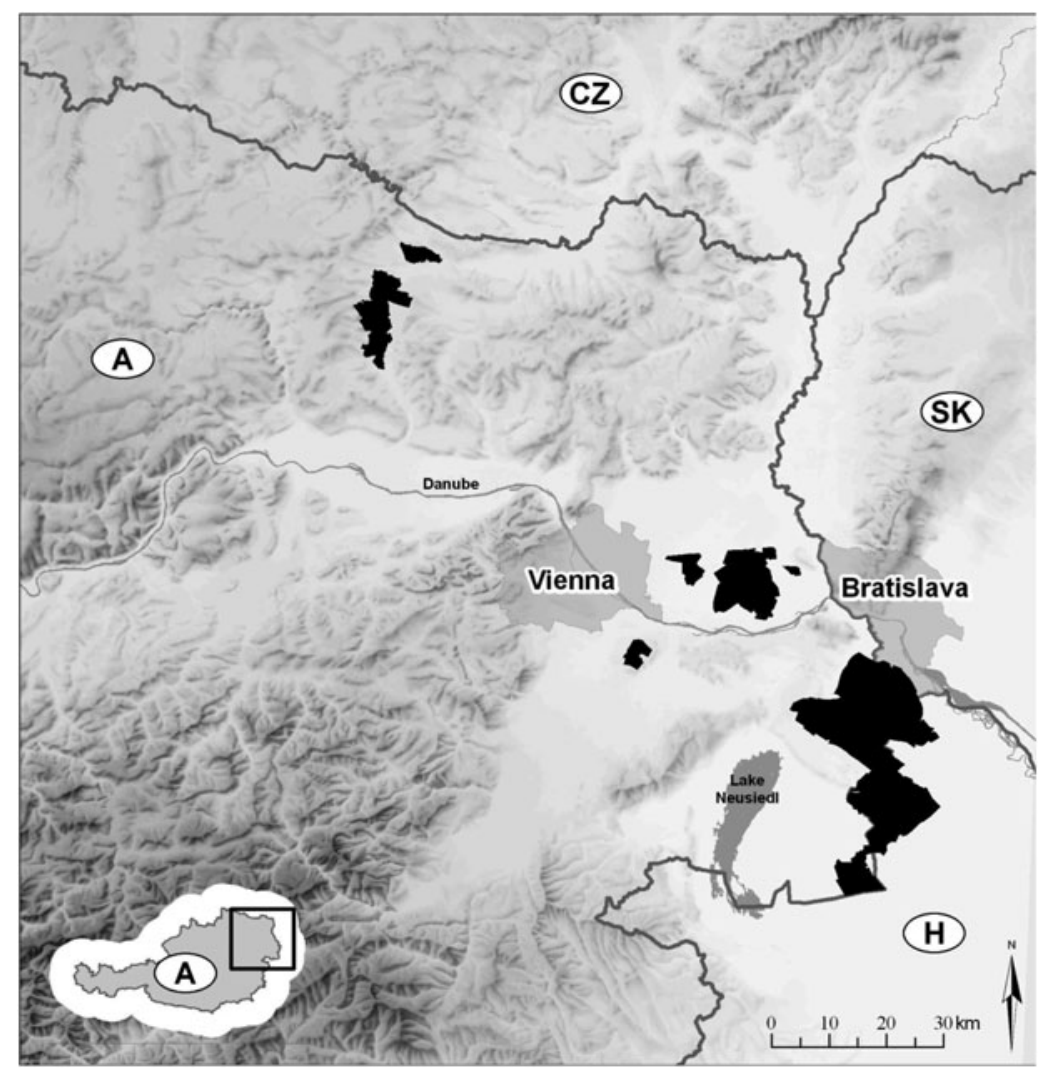

Figure 1. Austrian and Hungarian parts of the West-Pannonian distribution area (marked black) of the Great Bustard considered in this study. 


\section{Underground cabling and marking of power lines}

To decrease collision risk of Great Bustards in Eastern Austria, high-voltage power lines were equipped with different markers within the LIFE project LIFEo5 NAT/A/oooo77 (www.grosstrappe. at). To enhance visibility of $380 \mathrm{kV}$ power lines for birds, the earth wire was marked with double black and white aviation marker balls (30 cm diameter; one marker per $25-30 \mathrm{~m}$ ), the conductors were marked with $30 \times 30 \mathrm{~cm}$ marker plates (one per 40-50 m) fixed between the duplex conductors, alternating between black and white in colour (Fig. 2a). Double black and white aviation marker balls were also used for $220 \mathrm{kV}$ power lines (one marker per $30-35 \mathrm{~m}$ earth wire and conductor; Fig. $2 \mathrm{~b}$ ); $110 \mathrm{kV}$ power lines were marked with $40 \mathrm{x} 10 \mathrm{~cm}$ marker plates (alternating in colour between black and white; one marker per $15 \mathrm{~m}$ earth wire and per 30-90 m conductor; Fig. $2 \mathrm{c}$ ).

In Western Hungary, the earth wires as well as the conductors of high- and medium voltage power lines were marked within the Hungarian LIFE project LIFEo4 NAT/HU/ooo1o9 (www.tuzok.hu) with bird flight diverters, which can reflect light under low light conditions. Two different types of bird flight diverters were used: a rectangular one ( $9 \times 15 \mathrm{~cm}$, one marker per $17-100 \mathrm{~m})$, which spins even in light wind (Fig. $2 \mathrm{~d}$ ) and a circular one ( $13 \mathrm{~cm}$ diameter, one marker per $17-100 \mathrm{~m})$, which fluoresces up to to hours after sunset (Fig. 2e).

For all areas marked in Figure 1, high-voltage and medium-voltage power lines were digitised using the software package (ArcMap 9.1, ESRI) and total power line length was measured annually. Due to the small sample size, we could not differentiate between different marker types in our analyses, but only classified power lines as marked and unmarked. At the beginning of this study in 2002 a total of $10.6 \mathrm{~km}$ of high-voltage power lines were equipped with markers. Between 2005 and 2011 a further $89.7 \mathrm{~km}(86.7 \mathrm{~km}$ high-voltage, $3.0 \mathrm{~km}$ medium-voltage power line) were marked. Additionally, a total of $43.1 \mathrm{~km}$ of underground cabling of medium-voltage power line was installed by 2011 , decreasing the total power line length in our study area from $356.5 \mathrm{~km}(249.2 \mathrm{~km}$ mediumvoltage and $107.3 \mathrm{~km}$ high-voltage power line) in 2002 to $313.4 \mathrm{~km}$ in 2011.

\section{Data collection}

Although mortality of West-Pannonian Great Bustards has been documented in great detail since 1996, in the present analysis we only considered data collected systematically since 2002, when
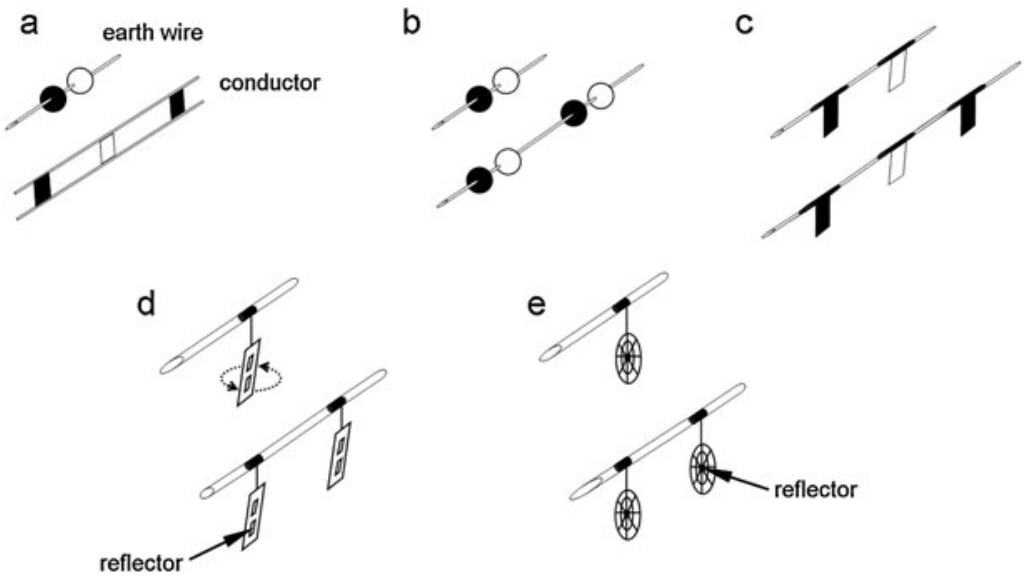

Figure 2. Design of wire markers at $380 \mathrm{kV}(\mathrm{a}), 220 \mathrm{kV}(\mathrm{b})$ and $110 \mathrm{kV}$ (c) high voltage power lines in Eastern Austria and design of rectangular (d) and circular (e) bird flight diverters used at high- and medium voltage power lines in Western Hungary, attached to the earth wire and conductor, respectively. 
intensive activities to protect the West-Pannonian population of the Great Bustard began within the framework of Rural Development Programmes in Lower Austria (since 2002: LE) and Burgenland (2002-2006: INTERREG; 2007-2010: LPF), and the LIFE projects LIFEo4 NAT/HU/ooo109 (20042008; www.tuzok.hu), LIFEo5 NAT/A/oooo77 (2005-2010), and LIFEog NAT/AT/ooo225 (since 2010; www.grosstrappe.at). Due to increasing awareness among hunters and farmers, bustards found dead in the field were reported with a much higher likelihood than before 2002.

\section{Data analyses}

Annual mortality rate of the Great Bustard population in our study area was defined as the number of individuals that were found dead in the respective year, divided by the total number of bustards present in the study area between April and May (Raab et al. 2010). We did not include young bustards found dead, which were still unable to fly. To calculate the annual mortality due to power line collisions, we considered only power line collision casualties. One year was not defined as calendar year but as the period from I June until 31 May of the following year.

Linear regression analyses were calculated to test if (I) total annual mortality rate, (2) annual mortality caused by power line collisions and (3) annual mortality caused by other reasons, changed from 2002 to 2011. Spearman rank correlations were used to test for effects of underground cabling (quantified as underground power line length) and length of marked power lines in the respective years on the annual mortality rate (considering power line collision victims only). Additionally, we used a paired Wilcoxon test to evaluate differences in the mean number of bustards colliding yearly with marked and unmarked power lines. Finally, we calculated GLMs (with normal error distribution and log-link function) testing for effects on annual mortality rate due to power line collisions, including the variables annual length of underground cables and marked power lines, and both variables separately. The three models were ranked according to their corrected Akaike information criterion $\left(\mathrm{AIC}_{\mathrm{c}}\right)$ values.

\section{Results}

Between I June 2002 and 31 May 2011 a total of 78 dead individuals were reported, of which $41.0 \%$ ( 32 birds) referred to Great Bustards which collided with power lines. Mean annual mortality rate $( \pm \mathrm{SD})$ between 2002 and 2010 was 3.5 ( \pm 1.6$) \%$, mean annual collision rate was $1.6 \pm(1.3) \%$. The significant decline in the total mortality rate observed from 2002 to 2011 (Fig. 3a) is mainly due to a strongly decreasing proportion of bustards colliding with power lines (Fig. 3 b). The proportion of birds that died due to other reasons remained rather similar over the study period (Fig. 3c).

Annual mortality rate due to power line collisions declined significantly with increasing length of underground power lines (Spearman rank correlation: $r_{\mathrm{s}}=-0.84, P=0.005$ ) and with increasing length of marked power lines $\left(r_{\mathrm{s}}=-0.76, P=0.017\right)$. The number of bustards colliding with power lines was significantly lower at marked than at unmarked power line sections (paired Wilcoxon test: $Z=2.07, P=0.038$; Fig. 4).

Underground cabling had a prominent effect on Bustard mortality caused by power line collisions as indicated by the model selection. The GLM including the variable underground cabling only achieved the lowest $\mathrm{AIC}_{\mathrm{c}}$ value (26.21) and a much higher $\mathrm{AIC}_{\mathrm{c}}$ weight $(0.743)$ than models containing both variables $\left(\mathrm{AIC}_{\mathrm{c}}=29.43, \mathrm{AIC}_{\mathrm{c}}\right.$ weight $\left.=0.148\right)$ or only the variable power line marking $\left(\mathrm{AIC}_{\mathrm{c}}=30.06, \mathrm{AIC}_{\mathrm{c}}\right.$ weight $\left.=0.108\right)$.

\section{Discussion}

Although Great Bustards tend to avoid areas near power lines when selecting suitable habitats (Lane et al. 2001) and are able to adapt their flight behaviour (Raab et al. 2011), collisions with overhead power lines still represented an important mortality factor in our study area during 

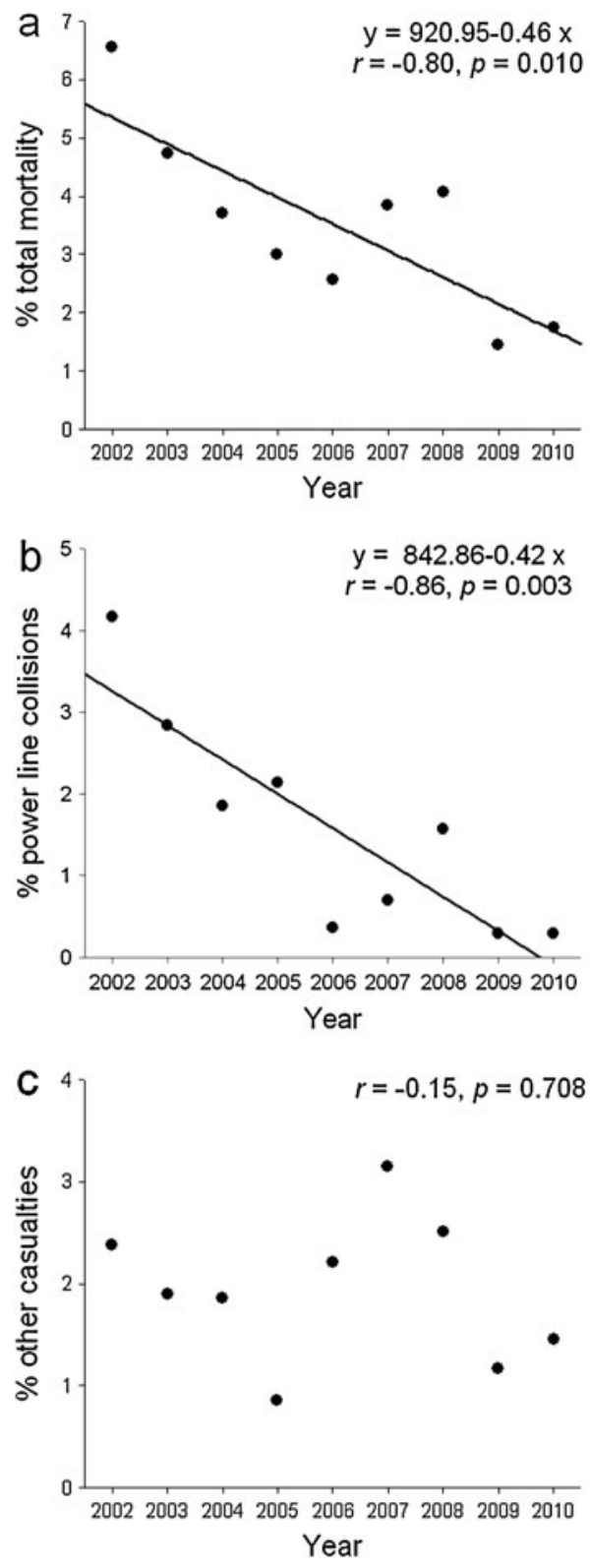

Figure 3. Change of (a) total mortality rate, (b) mortality caused by power line collisions and (c) other casualties of West-Pannonian bustards between 2002 and 2011.

recent decades (Faragó 1981, Reiter 2000, own unpubl. data). The mean annual collision rate of $1.6 \%$ documented by our study for the time period 2002-2011 is similar to the collision rate of $2.2 \%$ recorded for the national population of Portugal (Infante et al. 2005).

Our results clearly indicate that Great Bustard mortality rate declined significantly in the two years following the first underground cabling and power line marking measures. Although power line marking appeared to reduce the collision risk, underground cabling explained most of the reduced mortality after implementation of these two conservation measures. The effect of the 


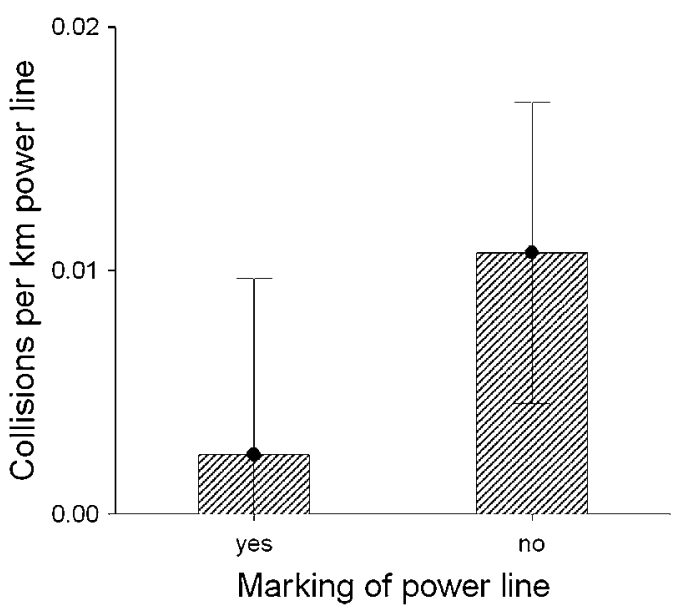

Figure 4. Difference of mean annual number of bustard collisions $( \pm$ SD) per km marked and unmarked power lines ( $n=9$ years).

latter was so prominent that in our modelling approach, the GLM containing only the variable underground cabling performed best of all models. Although the general importance of power line marking as a conservation measure to reduce collision risk should not be underestimated (e.g. Alonso et al. 1994), its efficacy varies with species and can be particularly low for birds such as bustards (Jenkins et al. 2010). Furthermore, the effectiveness of marking also depends on the design of markers (Jenkins et al. 2010, Janss and Ferrer 1998). Unfortunately, our dataset is too small to allow for more detailed analyses quantifying effects of marker design on collision risk of Great Bustards in our study area.

The conservation measures implemented to reduce collision casualties in our study area most likely contributed to the continuous increase of the West-Pannonian Great Bustard population (Raab et al. 2010). Indeed, the relatively small number of bustards found to have collided with power lines, might give a rather incomplete account. The mortality caused by power line collision is supposedly much higher than suggested by the casualties discovered in the field. An unknown proportion of carcasses may not have been found in higher vegetation or may have been carried away by carrion-feeding mammals. However, it is unlikely that the completeness of annually reported casualties changed during the period of our study due to a more or less unchanged number of recorders (predominantly farmers and hunters). Therefore, the declining mortality rate of power line victims should reflect a real decline in the risk of power line collisions. Besides a reduced collision risk, underground cabling may additionally have contributed to the recovery of the West-Pannonian Great Bustard population by providing access to potentially suitable habitats that were not used before, because Great Bustards appear to avoid the vicinity of power lines (Lane et al. 2001).

The two conservation measures, power line marking and underground cabling, were implemented in the most important West-Pannonian Great Bustard habitats and across highly frequented flight routes. Our results demonstrate that these measures successfully decreased the mortality rate of Great Bustards within a short time period. The extensive underground cabling representing $43.1 \mathrm{~km}$ of medium-voltage power lines and the marking of $89.7 \mathrm{~km}$ high-voltage power lines were realised at costs of $€_{3.02}$ million and $€_{1}$.O1 million respectively. The average costs of underground cabling of medium-voltage power lines and marking of high-voltage power lines were $€_{70,000}$ (min-max: $\left.€_{50,000-100,000}\right)$ and $€_{11,700}\left(€_{9,200-16,700}\right)$ per km power line. Unfortunately, the underground cabling of high-voltage power lines appears to be not practicable due to tremendously high costs (more than $€$ 0.7-1.o million per km) and technical 
difficulties. Therefore, we recommend underground cabling of medium-voltage power lines as one priority conservation measure in Great Bustard areas, while high-voltage power lines should be equipped with markers. Not only bustards but also other larger bird species may significantly benefit from such conservation measures.

\section{Acknowledgements}

This paper is a result of data collected in the framework of the LIFE Projects "Cross-border Protection of the Great Bustard in Austria" (LIFEo5 NAT/A/oooo77, LIFEog NAT/AT/ooo225; www.grosstrappe.at) and "Conservation of Otis tarda in Hungary" (LIFEo4 NAT/HU/oooiog, www.tuzok.hu). These projects were supported by the EU, many project partners and co-financiers. Additional EU co-financed projects (INTERREG-III: HUBP 5 M2_Oo15; LPF: 5-N-A1025/148-2009 and LE: RU5-LE-040/ooo, RU5-LE-152/ooo and RU5-S-428/o01-2005) were supported by the Austrian Federal Ministry for Agriculture, Forestry, Environment and Water management (BMLFUW) and the regional governments of Lower Austria and Burgenland. We are grateful to more than 700 people involved in conservation projects for the West-Pannonian Great Bustard population and who reported the majority of Great Bustard casualties found in the field.

\section{References}

Alonso, J. C., Alonso, J. A. and Muñoz-Pulido, R. (1994) Mitigation of bird collisions with transmission lines through groundwire marking. Biol. Conserv. 67: 129-134.

Alonso, J. C., Martín, A. C., Palacín, C., Martín, B. and Magña, M. (2005) The Great Bustard Otis tarda in Andalusia, Southern Spain: status, distribution and trends. Ardeola 52: 67-78.

Ballasus, H. and Sossinka, R. (1996) The impact of power lines on field selection and grazing intensity of wintering Whitefronted- and Bean Geese Anser albifrons, A. fabalis. J. Ornithol. 138: 215-228.

Barrios, L. and Rodríguez, A. (2004) Behavioural and environmental correlates of soaring-bird mortality at on-shore wind turbines. J. Appl. Ecol. 41: 72-81.

Bevanger, K. (1995) Estimates and population consequences of tetraonid mortality caused by collisions with high tension power lines in Norway. J. Appl. Ecol. 32: 745-753.

Bevanger, K. (1998) Biological and conservation aspects of bird mortality caused by electricity power lines: a review. Biol. Conserv. 86: 67-76.

Bevanger, K. and Brøseth, H. (2004) Impact of power lines on bird mortality in a subalpine area. Anim. Biodiv. Conserv. 27: 67-77.

Brown, W. M. and Drewien, R. C. (1995) Evaluation of two power line markers to reduce crane and waterfowl collision mortality. Wildlife Soc. Bull. 23: 217-227.

De La Zerda, S. and Rosselli, L. (2003) Mitigation of collisions of birds with hightension electric power lines by marking the ground wire. Ornithol. Columbiana 1: $42-62$.

Drewitt, A. L. and Langston, R. H. W. (2008) Collision effects of wind-power generators and other obstacles on birds. Ann. N. Y. Acad. Sci. 1134: 233-266.

Faragó, S. (1981) Villanyvezetékek okozta túzokpusztulások a Hanságban. Madártani Tájékoztató 1981 (July-September): 136-137.

Frost, D. (2008) The use of 'flight diverters' reduces mute swan Cygnus olor collision with power lines at Abberton Reservoir, Essex, England. Conserv. Evidence 5: 83-91.

Haas, D., Nipkow, M., Fiedler, G., Handschuh, M., Schneider-Jacoby, M. and Schneider, R. (2006) Caution: Electrocution! NABUGerman Society for Nature Conservation. Downloaded from http://www.nabu.de/ vogelschutz/caution_electrocution.pdf on 15/02/2010

IUCN (2010) The IUCN Red List of threatened species. Version 2010.4. Downloaded from http://www.iucnredlist.org on 11/05/2011.

Infante, S., Neves, J., Ministro, J. and Brandão, R. (2005) Estudo sobre o impacto das linhas 
eléctricas de média e alta tensão na avifauna em Portugal. Castelo Branco, Portugal: Quercus Associação Nacional de Conservação da Natureza e SPEA Sociedade Portuguesa para o Estudo das Aves. http://portal. icnb.pt/NR/rdonlyres/Ao4AE662-7439-4 FF6-AoD4-Eo162DoA9245/o/PORImpacto_ LinhasElectricas_2005.pdf. [Accessed: 12 June 2010].

Janss, G. F. E. (2000) Avian mortality from power lines: a morphologic approach of species-specific mortality. Biol. Conserv. 95: 353-359.

Janss, G. F. E. and Ferrer, M. (1998) Rate of bird collision with power lines: effects of conductor marking and static wire-marking. J. Field Ornithol. 69: 8-17.

Jenkins, A. R., Smallie, J. J. and Diamond, M. (2010) Avian collisions with power lines: a global review of causes and mitigation with a South African perspective. Bird Conserv. Internatn. 20: 263-278.

Lane, S. J., Alonso, J. C. and Martín, C. A. (2001) Habitat preferences of great bustard Otis tarda flocks in the arable steppes of central Spain: are potentially suitable areas unoccupied? J. Appl. Ecol. 38: 193203.

Martín, C. A., Alonso, J. C., Alonso, J. A., Palacín, C., Magña, M. and Martín, B. (2007) Sex-biased juvenile survival in a bird with extreme size dimorphism, the Great Bustard Otis tarda. J. Avian Biol. 38: 335-346.
Newton, I. (2007) Weather-related massmortality events in migrants. Ibis 149: 453-467.

Raab, R., Kollar, H. P., Winkler, H., Faragó, S., Spakovszky, P., Chavko, J., Maderič, B., Škorpíková, V., Patak, E., Wurm, H., Julius, E., Raab, S. and Schütz, C. (2010) Development of the West Pannonian population of the Great Bustard, Otis tarda Linnaeus 1758, from 1900 to the winter 2008/2009. Egretta 51: 74-99.

Raab, R., Spakovszky, P., Julius, E., Schütz, C. and Schulze, C. H. (2011) Effects of power lines on flight behaviour of the WestPannonian Great Bustard Otis tarda population. Bird Conserv. Internatn. 21: 142-155.

Reiter, A. S. (2000) Casualties of Great Bustards (Otis tarda L.) on overhead power lines in the western Weinviertel (Lower Austria). Egretta 43: 37-54.

Rollan, A., Real, J., Bosch, R., Tintó, A. and Hernández-Matías (2010) Modelling the risk of collision with power lines in Bonelli's Eagle Hieraaetus fasciatus and its conservation implications. Bird Conserv. Internatn. 20: 279-294.

Yee, M. J. (2008) Testing the effectiveness of an avian flight diverter for reducing avian collisions with distribution power lines in the Sacramento Valley, California. California Energy Commission. Downloaded from www. energy.ca.gov/2007publications/CEC-5002007-122/CEC-500-2007-122.PDF on 15/ $02 / 2010$

\section{RAINER RAAB*, CLAUDIA SCHÜTZ, EIKE JULIUS}

Technisches Büro für Biologie, Quadenstraße 13, A-2232 Deutsch-Wagram, Austria.

\section{PÉTER SPAKOVSZKY}

University of West Hungary, Institute of Wildife Management and Vertebrate Zoology, H-940o Sopron, Ady E. u. 5, Hungary and Technisches Büro für Biologie, Quadenstraße 13, A-2232 Deutsch-Wagram, Austria.

\section{CHRISTIAN H. SCHULZE}

Department of Animal Biodiversity, University of Vienna, Rennweg 14, A-1030 Vienna, Austria.

*Author for correspondence; e-mail: rainer.raab@gmx.at 